\title{
Mechanical stimulation of epithelial cells using polypyrrole microactuators.
}

\author{
Karl Svennersten, Magnus Berggren, Agneta Richter-Dahlfors and Edwin W H Jager
}

\section{Linköping University Post Print}

N.B.: When citing this work, cite the original article.

Original Publication:

Karl Svennersten, Magnus Berggren, Agneta Richter-Dahlfors and Edwin W H Jager, Mechanical stimulation of epithelial cells using polypyrrole microactuators., 2011, Lab on a Chip, (11), 19, 3287-93.

http://dx.doi.org/10.1039/c1lc20436j

Copyright: Royal Society of Chemistry http://www.rsc.org/

Postprint available at: Linköping University Electronic Press http://urn.kb.se/resolve?urn=urn:nbn:se:liu:diva-70442 


\title{
Mechanical Stimulation of Epithelial Cells Using Polypyrrole Microactuators
}

\author{
Karl Svennersten $^{a}$, Magnus Berggren ${ }^{\mathrm{b}}$, Agneta Richter-Dahlfors ${ }^{\mathrm{a}}$ and Edwin W.H. Jager $^{* \mathbf{b}}$ \\ Received (in $X X X, X X X)$ Xth $X X X X X X X X X 20 X X$, Accepted Xth $X X X X X X X X X 20 X X$ \\ ${ }_{5}$ DOI: $10.1039 / b 000000 x$
}

The importance of mechanotransduction for physiological systems is becoming increasingly recognized. The effect of mechanical stimulation is well studied in organs and tissues, for instance by using flexible tissue culture substrates that can be stretched by external means. However, on the cellular and subcellular level dedicated technology to apply appropriate mechanical stimuli is limited. Here, we report an organic

10 electronic microactuator chip for mechanical stimulation of single cells. These chips are manufactured on silicon wafers using traditional microfabrication and photolithography techniques. The active unit of the chip consists of the electroactive polymer polypyrrole that expands upon the application of a low potential. The fact that polypyrrole can be activated in physiological electrolytes makes it well suited as the active material in a microactuator chip for biomedical applications. Renal epithelial cells, which are

15 responsive to mechanical stimuli and relevant from a physiological perspective, are cultured on top of the microactuator chip. The cells exhibit good adhesion and spread along the surface of the chip. After culturing, individual cells are mechanically stimulated by electrical addressing of the microactuator chip and the response to this stimulation is monitored as an increase in intracellular $\mathrm{Ca}^{2+}$. This $\mathrm{Ca}^{2+}$ response is caused by an autocrine ATP signalling pathway associated with mechanical stimulation of the cells. In 20 conclusion, the present work demonstrates a microactuator chip based on an organic conjugated polymer, for mechanical stimulation of biological systems at the cellular and sub-cellular level.

\section{Introduction}

The ability to sense mechanical stimuli represents one of the most conserved sensory mechanisms of living organisms. Numerous 25 mechano-sensing mechanisms have been developed throughout evolution of plants, animals, and unicellular organisms, which illustrates the importance of cells to be able to respond and adapt to mechanical cues, no matter their location. In higher order organisms, mechano-sensing is critical to initiate and regulate 30 numerous vital functions, such as hearing, touch, cardiac output, and urine flow. ${ }^{1-3}$

Being a primary location for mechano-sensing, the plasma membrane is equipped with several systems that enable sensing of mechanical stimuli. One pathway involves cellular adhesion 35 complexes, via which the cytoskeleton, and associated intracellular signal-transduction pathways mediate mechanosensing. ${ }^{4}$ The plasma membrane also harbors ion channels with intrinsic mechano-sensing properties, which are present in eukaryotic as well as prokaryotic cells. ${ }^{5-7}$ When exposed to 40 mechanical stress, cells may respond by the release of purines such as adenosine-5'-triphosphate (ATP). ${ }^{8}$ ATP signals via metabotropic or ionotropic purinergic receptors, which utilize $\mathrm{Ca}^{2+}$ as second messenger. ${ }^{8}$ This auto- and paracrine mode of ATP signaling is especially important in tissues subjected to fluid 45 flow such as the vasculature and urinary tract. ${ }^{9-12}$
As knowledge in the area of cellular mechanotransduction has expanded, the eukaryotic cell is now viewed as a highly active and complex mechanical structure. ${ }^{13}$ Data to support this concept has been generated using a variety of techniques. Shear flow 50 represents a mechanical stress present in physiological niches such as the vasculature, cochlea, and urinary tract and is conceptually straight forward to apply using cell culture flow chambers. ${ }^{14}$ Another method to apply mechanical stress to a cell culture is the use of flexible-bottomed cell culture plates that are 55 actuated by an externally applied vacuum pressure (Flexcell ${ }^{\circledR}$ system). ${ }^{15}$ The Flexcell ${ }^{\circledR}$ system has been proven useful in areas such as tissue engineering and chronic inflammation. ${ }^{16,17}$ Optical tweezers $^{18,19}$ and atomic force microscopy (AFM) $)^{20}$ have been used to apply forces represented by poking and pulling of cells. ${ }_{60}$ Strain to specific receptors can be achieved using ferromagnetic beads of various size conjugated to ligands for the receptors and actuated by externally applied magnetic field. ${ }^{21}$

Although systems like the Flexcell ${ }^{\circledR}$ and flow chambers provide well established ways to induce physiologically relevant 65 mechanical stress to cell and tissue cultures, they do not have the precision to exclusively address individual cells within a cluster or tissue. This is in contrast to optical tweezers and atomic force microscopy which do allow single cell stimulation but are restricted to apical stimulation which is disparate to many 70 physiological situations, where mechanical strain is propagated via the connective tissue to the basal side of the cells. Hence, 


\section{Cite this: DOI: $10.1039 / \mathrm{c0xx00000x}$}
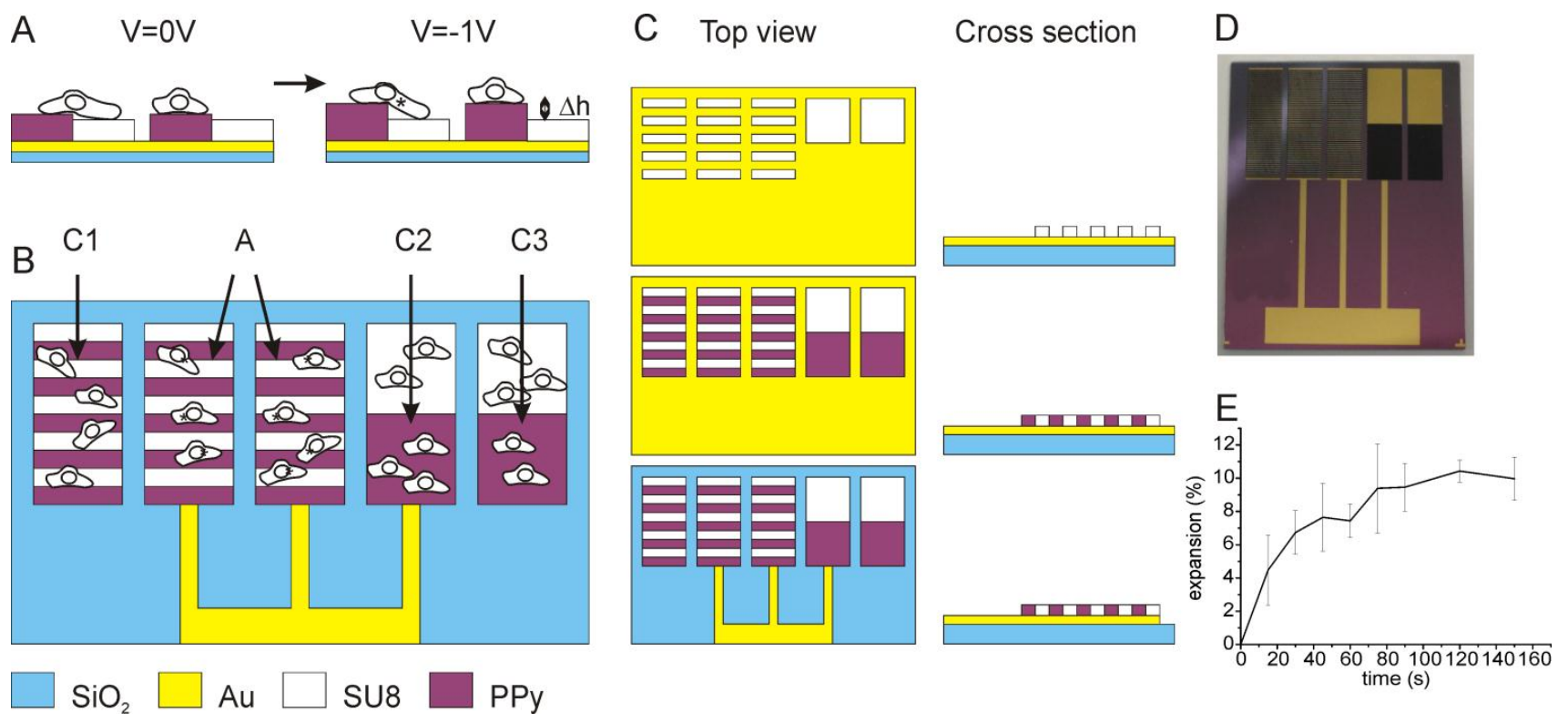

Fig.1 Design and fabrication of the mechanical stimulation chip. (A) Schematic illustration of the principle of in vitro mechanical stimulation using PPy microactuators. (B) Schematic illustration of the chip layout. A = PPy microactuator, C1 = passive patterned area, C2 = electroactive planar PPy area, C3 $5=$ passive planar PPy area. (C) Illustration of the chip fabrication steps, top view and cross section (along the center of the chip). Top: Deposition and patterning of SU-8 on an Au coated oxidised Si wafer. Middle: Electrosynthesis and patterning of PPy. Bottom: Wet chemical etching of Au to form the final electrode structure including electrical leads and contact pads. (D) A photograph of the mechanostimulation chip, $20 \mathrm{~mm}$ by $25 \mathrm{~mm}$ in size. (E) Ex situ measurement of the expansion (\%) of PPy microactuators in $0.1 \mathrm{M} \mathrm{NaDBS}$, at $\mathrm{V}=-1.0 \mathrm{~V}$ vs $\mathrm{Ag} / \mathrm{AgCl}$ and activated for $15 \mathrm{~s}$ for each measurement point.

10 there is a need to develop a technology that can mechanically actuate single cells, populations of cells, and tissues with a physiologically relevant stimulus via easy addressing. For the future development of this technology to be applied in vivo or as therapeutic implants, their operation must be simple and 15 independent of complicated external devices.

Conjugated polymers, such as polypyrrole (PPy) and polythiophenes are well suited for interfacing with biology. They are known to be biocompatible $\mathrm{e}^{22,23}$ and have been used to provide both sensing ${ }^{23,24}$ and electro-chemical stimulation of cells and 20 tissues. $^{25-27}$ In addition, conjugated polymers have been used to provide mechanical actuation on both the macro-scale ${ }^{28,29}$ and micro-scale..$^{30,31}$ This actuation is based on a volume change of the conjugated polymer that is predominantly caused by intercalation of ions during electrochemical reduction and 25 oxidation. The volume change of PPy doped with dodecylbenzenesulfonate (DBS) was shown to be highly anisotropic $^{32}$ and this much greater perpendicular volume change has previously been used in microfluidic valves ${ }^{33}$ and wettability switches. ${ }^{34}$ Since PPy (micro-) actuators can operate in 30 biologically relevant electrolytes including cell culture media and blood, they have also been utilized as active components in medical devices. ${ }^{35}$

To improve on available techniques for mechanic stimulation of single cells in cultures, we have developed a chip comprising ${ }_{35}$ PPy-based microactuators. Its design includes active areas adjacent to passive control areas, to allow for experimental design that includes intrinsic controls. The chip is designed to meet the standards of cell culturing conditions, as well as microscopy analysis. The use of the chip for real-time recordings of 40 intracellular $\mathrm{Ca}^{2+}$ signalling and accompanying effects on the actin cytoskeleton as a response to mechanical stimulation is demonstrated.

\section{Materials and Methods}

\section{Microactuator fabrication}

${ }_{45}$ Pyrrole monomer solution was obtained from Sigma-Aldrich, distilled upon arrival, and stored at $-20{ }^{\circ} \mathrm{C}$ until further use. Sodium dodecylbenzenesulfonate (NaDBS) was obtained from TCI Europe (Zwijndrecht, NL). A thin adhesion layer of $50 \AA \mathrm{Cr}$ and thick conducting layer of $1000 \AA \mathrm{Au}$ were thermally 50 evaporated on an oxidised $100 \mathrm{~mm}$ silicon wafer. Next, the passive structures were photopolymerised by applying a $10 \mu \mathrm{m}$ layer of SU-8-2010 (Fig. 1C top). Herefter, polypyrrole was electrosynthesized from a $0.1 \mathrm{M}$ pyrrole and $0.1 \mathrm{M}$ NaDBS solution at a constant potential of $0.57 \mathrm{~V}$ vs $\mathrm{Ag} / \mathrm{AgCl}$ using a ${ }_{55}$ three electrode set-up with a Au coated $\mathrm{Si}$ wafer as the counter 
electrode and an Ecochemie microAutolabIII (Metrohm Autolab, Utrecht, NL) potentiostat. The PPy layer was patterned by covering the $\mathrm{Au}$ coated wafer with a photoresist pattern that contained openings where the PPy should be applied (Fig. 1C 5 middle). Finally, the Au pattern comprising the electrical leads and contact pad was wet chemically etched using standard $\mathrm{Au}$ and $\mathrm{Cr}$ etching solutions (Fig. 1C bottom).

\section{Microactuator characterization}

The device was electrochemically actuated using a 3 electrode 10 set-up with a $\mathrm{Au}$ counter electrode and a $\mathrm{Ag} / \mathrm{AgCl}$ reference electrode. A constant potential of $-1.0 \mathrm{~V}$ for $300 \mathrm{~s}$ was applied to the device in either an aqueous $0.1 \mathrm{M} \mathrm{NaDBS}$ solution or DMEM cell culture media. For the expansion profile measurement, the device was activated for $15 \mathrm{~s}$ at $-1.0 \mathrm{~V}$ for each measurement 15 point. Ex situ thickness measurements were taken using a Dektak 3ST surface profiler (Veeco Instruments, Plainview, NY, USA). After, an activation the device was removed from the electrochemical cell, rinsed with DI water, and dried using an airgun. Quickly thereafter, a profile scan was taken. In case of the

20 expansion profile or cycling measurements, the device was reconnected in the electrochemical cell for the next activation step.

\section{Cell culture}

The epithelial cell line MDCK (ATCC, no. CCL-34), was 25 propagated in DMEM (Sigma) supplemented with $10 \%$ FBS (Sigma), $2 \%$ Hepes buffer (Sigma), L-Glutamin (0.3 g dm-3, Sigma) and penicillin;streptomycin (100 U ml-1; $100 \mu \mathrm{g} \mathrm{ml-1,}$ Sigma). Cells were detached from the cell culturing flask with Trypsin-EDTA (0.5 g dm-3 trypsin $0.2 \mathrm{~g} \mathrm{dm}\urcorner 3$ EDTA in PBS, ${ }_{30}$ Sigma) and washed once in DMEM, before $3 \mathrm{ml}$ cell suspension $(1.0-3.0 \times 105$ cells ml-1) were seeded on fibronectin coated 5 $\mu \mathrm{g} \mathrm{cm}$-2(Sigma) microactuator devices placed in $30 \mathrm{~mm}$ cell culture dishes (Sarstedt). Cells were incubated in a humidified 37 ${ }^{\circ} \mathrm{C}, 5 \% \mathrm{CO}_{2}$ cell incubator.

\section{${ }_{35}$ Cell stimulation}

To perform mechanical stimulation the chip comprising the cells was mounted in a customized chamber and prewarmed $\left(37{ }^{\circ} \mathrm{C}\right)$ DMEM without supplement was added. The mechanical stimulation chips were operated using a Gamry potentiostat with ${ }_{40}$ Gamry PHE200 software. For $\mathrm{Ca}^{2+}$ imaging a $300 \mathrm{~s}$ stimulation of $-1.0 \mathrm{~V}$ was followed by a period of $300 \mathrm{~s}$ at $0.0 \mathrm{~V}$ against the $\mathrm{Ag} / \mathrm{AgCl}$ reference electrode. For immunostaining and SEM experiments cells were immediately fixed after $300 \mathrm{~s}$ stimulation of $-1.0 \mathrm{~V}$.

\section{${ }_{45} \mathrm{Ca}^{2+}$ imaging}

Loading of cells with Fura-2 was performed during 40 min incubation at $37{ }^{\circ} \mathrm{C}$ in DMEM with $2 \mu \mathrm{M}$ Fura-2-AM. Samples were mounted on a Nikon upright Eclipse 80i microscope with a CFI Fluor DLL 40X dip down objective for ratiometric $\mathrm{Ca}^{2+}$ 50 imaging. Excitation at 340 and $380 \mathrm{~nm}$ was achieved with a DeltaRAM illuminator and a DeltaRAM-V monochromator with a computer controlled SC-500 shutter controller. Emission (510 $\mathrm{nm})$ was collected with a Photometrics Coolsnap CCD camera. Data were analysed using Image J (U. S. National Institutes of ${ }_{55}$ Health).

\section{Immunostaining and analysis}

After stimulation cells were fixed in $3.7 \%$ formaline. Actin filaments of cells on the mechanical stimulation chip were stained with TRITC-phalloidin (Sigma). Nuclei were stained with 60 Hoechst 33258 (Molecular Probes). Specimens were analyzed in an Olympus FV1000 Confocal microscope. Profile scan was conducted using Image J (U.S. National Institutes of Health) and plotted using $\mathrm{R}$.

\section{Scanning electron microscopy}

65 After stimulation cells were fixed in $2 \%$ glutaraldehyde complemented with $0.1 \mathrm{M}$ sodiumcacodylate buffer, $0.1 \mathrm{M}$ sucrose and $3 \mathrm{mM} \mathrm{CaCl} 2$, pH 7.4, washed with PBS and dried in air at room temperature. Sample was mounted on a SEM stub, coated with gold and imaged in a Philips 1500 SEM microscope.

\section{${ }_{70}$ Results}

\section{Design of the mechanical stimulation chip}

The chip is designed to provide mechanical stimulation to cells using PPy microactuators. The microactuators A have been designed as patterned lines of the electroactive polymer PPy 75 alternated with the passive structure consisting of SU-8. Upon application of a potential, the PPy lines will expand vertically and thus mechanically stimulate cells that are situated along the borders, i.e. that adhere to both the PPy and SU-8 (Fig. 1A). Cells that are located on only PPy or SU-8 are not mechanically 80 stimulated. Based on the mean diameter of Madin-Darby Canine Kidney (MDCK) renal epithelial cells $(\sim 50 \mu \mathrm{m})$, a line width of $100 \mu \mathrm{m}$ is chosen. This is to assure that a significant fraction of cells position themselves across a border, while at the same time minimizing the risk of cells able to position themselves across 85 multiple borders. The chip further comprises three different areas for internal control experiments, designated $\mathrm{C} 1$ to $\mathrm{C} 3$ (Fig. 1B). The control area $\mathrm{C} 1$ is a passive patterned area with the same structural composition as the microactuator A, but without electrical addressing. This area thus serves as a control for 90 cellular responses induced by the materials and topography per se, since it will not be activated when a potential is applied to the chip. The control area $\mathrm{C} 2$ is designed to investigate any effects of electrochemical addressing. As C2 is an electroactive planar area consisting of one large PPy surface adjacent to one SU-8 surface, 95 it only has one border. Therefore, the majority of cells will accordingly position themselves on a planar surface, and not across a border. Cells situated on the PPy surface will receive the same electrochemical stimulation as cells on the microactuator A, but not be mechanically stimulated. Finally, C3 is a passive 100 planar PPy area which is structurally similar to C2 but lacks electrical addressing, in order to investigate passive surface effects on the cells. Thus it is posing as a negative control for both patterning and activation potential.

The chips, $20 \mathrm{~mm}$ by $25 \mathrm{~mm}$ in size, were fabricated using 105 standard photolithography and microfabrication methods (Fig. 1C and D). First, a $10 \mu \mathrm{m}$ thick SU-8 layer was deposited on an $\mathrm{Au}$ coated oxidised Si wafer. Next, PPy doped with DBS was electrosynthesized, resulting in smooth PPy layers. The PPy thickness varied slightly between different batches, having an 110 average thickness of $11.0 \pm 0.6 \mu \mathrm{m}($ mean $\pm \mathrm{sd}, \mathrm{n}=6)$. Finally, the 
electrical leads and contact pads were wet-chemically etched and the wafers were finally diced.

\section{Device characterisation}

To evaluate the perpendicular expansion of PPy upon electrical 5 stimulation of the microactuator A, a topography profile scan was conducted using a DekTak profilometer. The perpendicular expansion was measured on chips activated in well-defined $0.1 \mathrm{M}$ NaDBS electrolyte as well as on fibronectin coated chips
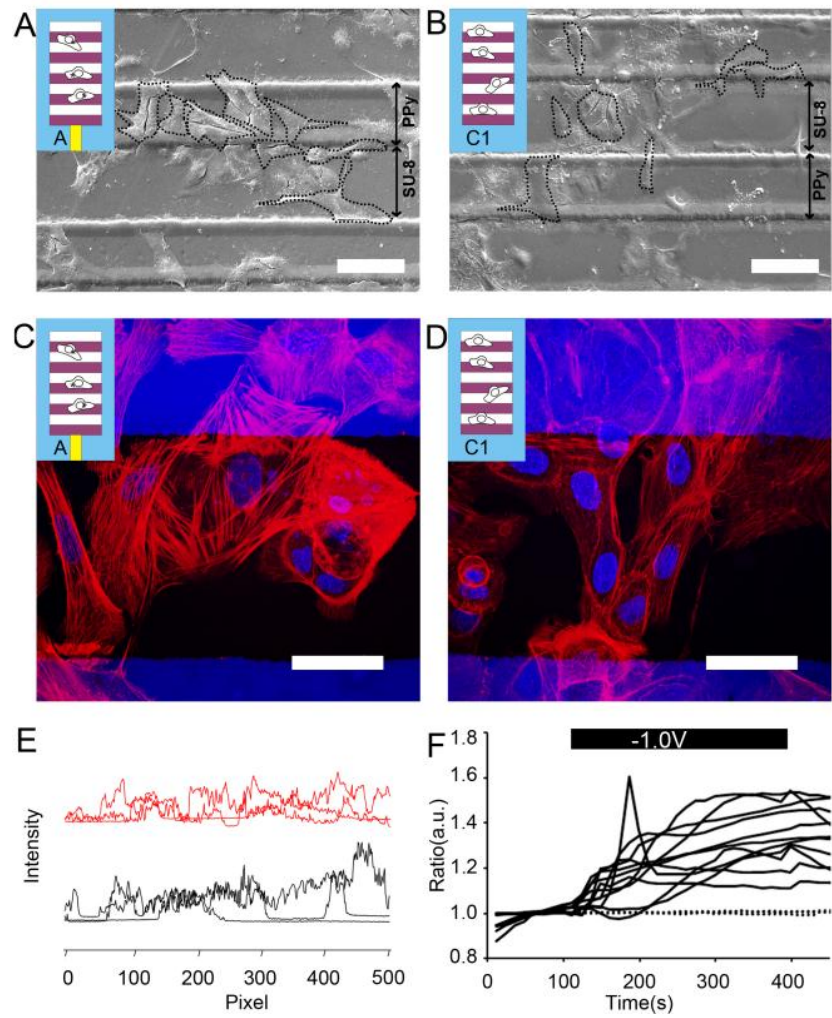

10 Fig. 2 The microactuator A vs, the passive patterned area C1 (inserts illustrating the investigated area). (A) SEM illustrating the morphology of adhered MDCK cells on microactuator A ( scale bar $=100 \mu \mathrm{m}$ ) and (B) on passive patterned area $\mathrm{C} 1$. The borders of some of the cells shown in the SEM pictures have been marked with a dotted line. Confocal 15 micrograph showing actin filaments (red) and nuclei (blue) on MDCK cells (C) on microactuator A ( scale bar $=50 \mu \mathrm{m}$ ) and (D) on passive patterned area $\mathrm{C} 1$. (E) Intensity line scans acquired parallel to PPy/SU-8 border. Three scans from different areas on the microactuator A (black line) and the passive patterned area $\mathrm{C} 1$ (red line) from the same chip are 20 presented. (F) Intracellular $\mathrm{Ca}^{2+}$ recordings of several cells on the microactuator A from five different experiments (solid line) and recordings from several cells on the passive patterned area $\mathrm{C} 1$ from three different experiments (dotted line).

activated in complex cell culture media. The perpendicular 25 expansion upon application of the potential ( $-1 \mathrm{~V}$ vs $\mathrm{Ag} / \mathrm{AgCl}$ for 5 mins) was $0.7 \pm 0.1 \mu \mathrm{m}$, i.e. $6.9 \pm 0.1 \%$ of the total PPy layer thickness, when activated in $0.1 \mathrm{M} \mathrm{NaDBS}$ and $1.0 \pm 0.4 \mu \mathrm{m}$ or $8.8 \pm 3.7 \%$, in cell culture media. This indicates that the microactuator A functions well under physiological conditions.

30 These expansion levels are lower than reported by others ${ }^{32,36}$, but well suited for cell stimulation experiments, as a displacement of $1 \mu \mathrm{m}$ can stimulate a cell without damaging it. The dynamics of the expansion, which is of importance for the cellular response, were investigated by taking profile scans every $15 \mathrm{~s}$. As can be
35 seen in Fig. 1E, the expansion reaches a plateau after about $90 \mathrm{~s}$. Contrary to previous results ${ }^{32,} 34$, we did not observe any shrinkage of the PPy(DBS) film during the re-oxidation nor during any of the following redox cycles.

\section{Mechanical stimulation of MDCK cells}

${ }_{40}$ Because surface topography can have an influence on cell adhesion and spreading onto surfaces we wanted to study the topography of the patterned areas on the chip and the distribution of MDCK cells on these. ${ }^{37}$ Cells were cultured overnight on fibronectin coated $\left(5 \mu \mathrm{g} \mathrm{cm}{ }^{-2}\right)$ chips. The chips where then 45 mounted for activation and cell culture media was changed. After activation of the chip
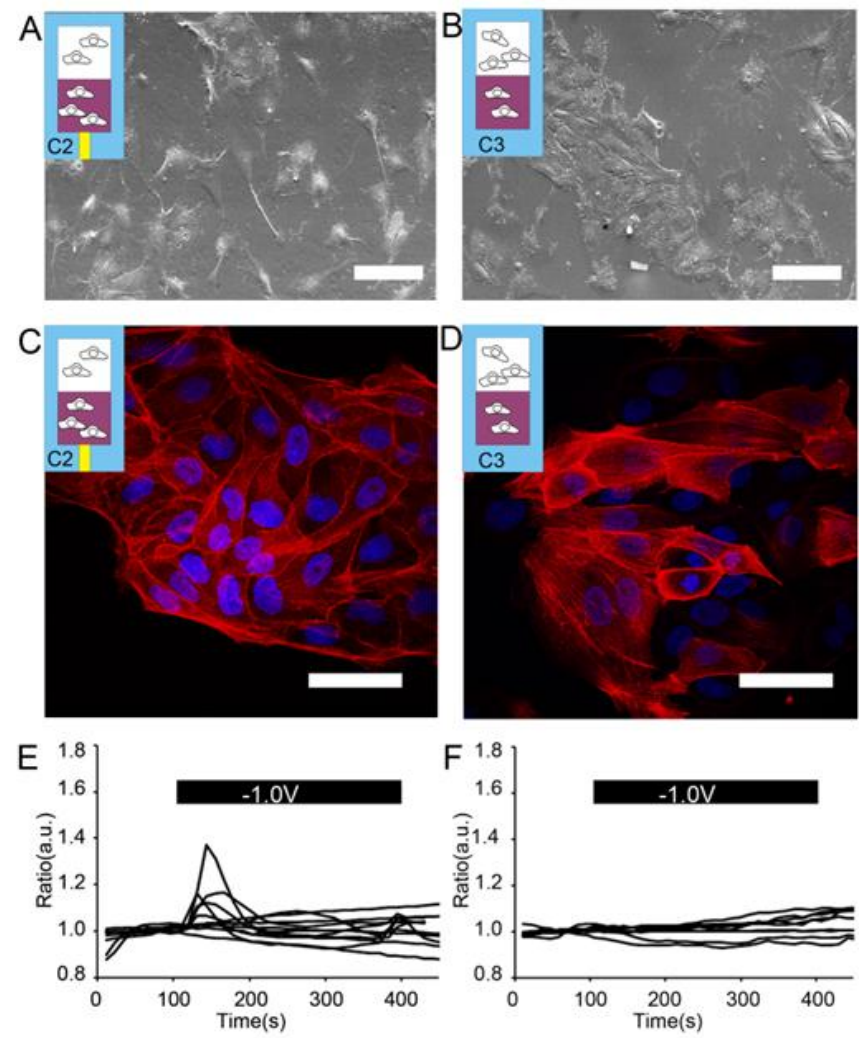

Fig. 3 Investigation of cells on planar control surfaces C2 and C3 (inserts illustrating the investigated area). SEM illustrating the morphology of 50 adhered MDCK cells (A) on electroactivated planar PPy area C2 ( scale bar $=100 \mu \mathrm{m})$ and (B) on passive planar PPy area C3. Confocal micrograph showing actin filaments (red) and nuclei (blue) (C) on MDCK cells on electroactivated planar PPy area C2 (scale bar $=50 \mu \mathrm{m}$ ) and (D) on passive planar PPy area $\mathrm{C} 3$. Intracellular $\mathrm{Ca}^{2+}$ traces from several cells 55 (E) on electroactived planar PPy area $\mathrm{C} 2$, recorded from four different experiments and $(\mathrm{F})$ on passive planar PPy area C3 from three different experiments.

for $300 \mathrm{~s}$ at $-1.0 \mathrm{~V}$ vs. $\mathrm{Ag} / \mathrm{AgCl}$, the chips were prepared for and imaged with a scanning electron microscope (SEM). In Fig. 2A 60 and $\mathrm{B}$ it can be seen that the cells adhere and spread on both the actuator $\mathrm{A}$ and passive patterned area $\mathrm{C} 1$, and that a large fraction of the cells span across a PPy/SU-8 border. This demonstrates that the line dimensions were properly chosen for our purposes and the spreading of the cells on the surface confirms firm cell 65 adhesion.Good adhesion is also confirmed by the ability of the cells to withstand the fluid flow associated with changing of cell culture media in the experimental procedures. 
The nucleus and the cytoskeleton are important structures of the cell and the morphology of these can say much about the status of a cell. These structures are commonly visualized using fluorescent staining. The border between the SU-8 and the PPy 5 can easily be identified in the fluorescence microscope due to the auto-fluorescent properties of SU-8. ${ }^{38}$ Cells were cultured and stimulated as described previously and thereafter prepared for immunofluorescence staining. On both the microactuator A and the passive patterned area $\mathrm{C} 1$ cells have normal nuclei and 10 developed actin stress fibers indicating healthy cells with good adhesion (Fig. 2C and D). The actin cytoskeleton is a fundamental part of the mechanical machinery of the cell. ${ }^{39}$ Therefore it is interesting to be able to compare the extent of the actin fibers on the microactuator surface and the control surface.

15 We investigated the actin fiber intensity by recording an intensity line scan perpendicular to the PPy/SU-8 border comparing the microactuator $\mathrm{A}$ and passive patterned area $\mathrm{C} 1$ from the same chip (Fig. 2E). Although, these measurements showed only minor differences in actin filament intensity upon mechanical 20 stimulation, it illustrates how cytoskeletal parameters may be investigated using the microactuator chip.

MDCK cells have previously been shown to respond to mechanical stimuli with increases in intracellular $\mathrm{Ca}^{2+}$. We wish to investigate whether the mechanical stimuli delivered via this 25 microactuator chip is sufficient to induce such responses. To assay the immediate response of live cells to the mechanical stimulation, cells were loaded with the $\mathrm{Ca}^{2+}$ dye Fura- 2 and imaged in real time, while the chip was activated for $300 \mathrm{~s}$ at -1.0 $\mathrm{V}$ vs $\mathrm{Ag} / \mathrm{AgCl}$, followed by $300 \mathrm{~s}$ at $0.0 \mathrm{~V}$ vs. $\mathrm{Ag} / \mathrm{AgCl}$. The 30 intracellular $\mathrm{Ca}^{2+}$ level in cells grown on the microactuator $\mathrm{A}$ was distinctly increased upon mechanical stimulation as compared to the cells on the passive patterned area $\mathrm{C} 1$ (Fig. 2F). The kinetics of the intracellular $\mathrm{Ca}^{2+}$ increase was rather slow but correlated well with the expansion dynamics (10-100 s) of the PPy

35 actuators, compare the results of Fig. 1E and Fig. 2F. In some cases a biphasic response was seen with an initial early peak followed by a relatively slower increase of intracellular $\mathrm{Ca}^{2+}$ associated with the swelling of the polymer (Fig. 2F). Some cells also showed a small fluctuation in $\mathrm{Ca}^{2+}$ at the $-1.0 \mathrm{~V}$ to $0.0 \mathrm{~V}$

40 transition which we tentatively explain by ion currents associated with the electrochemical switching.

\section{Impact of the addressing potential on the $\mathrm{Ca}^{2+}$ response}

Since the microactuator is operated by applying a voltage to the PPy material there is a risk that the observed $\mathrm{Ca}^{2+}$ increase is in 45 part or entirely induced by voltage-operated channels. To rule out a voltage-triggered mechanism we compared the microactuator $\mathrm{A}$ with the electroactive planar area $\mathrm{C} 2$. In contrast to microactuator A, cells on the electroactive planar PPy area C2 should not experience a mechanical stimulation, but receive the same 50 electrical addressing. Some cells on the electroactive planar area C2 showed peaks that coincided with the application of the voltage at time $=100 \mathrm{~s}$ (Fig. 3E). The switching from $-1.0 \mathrm{~V}$ to $0.0 \mathrm{~V}$ at $400 \mathrm{~s}$ also resulted in transient $\mathrm{Ca}^{2+}$ fluctuations in some cells (Fig. 3E). These $\mathrm{Ca}^{2+}$ peaks are different from the gradual 55 and persistent increase of intracellular $\mathrm{Ca}^{2+}$ seen in cells on the microactuator A (Fig. 2F) but not on the electroactive planar area $\mathrm{C} 2$ (Fig. 3E). This indicates that the gradual intracellular $\mathrm{Ca}^{2+}$ response on the microactuator $\mathrm{A}$ was indeed mechanically induced.

\section{${ }_{60}$ Cellular responses on the electroactive planar area $\mathrm{C2}$ and passive planar area $\mathrm{C} 3$}

Further investigations focused on the morphology of cells and surfaces of the planar areas C2 and C3 of the chip and the distribution of cells on these to see if these parameters differed ${ }_{65}$ from the patterned areas. Therefore SEM imaging was performed as described in the previous section. Both the electroactive planar area C2 (Fig. 3A) and the passive planar area C3 (Fig. 3B) had smooth surfaces and the structure of the PPy was similar to the patterned areas. Cells on the surfaces were distributed evenly 70 over both planar surfaces, similar to the distribution of cells on the patterned areas. Moreover, investigation of actin filaments and the nuclei of the cells showed that cells on the electroactivated planar area C2 (Fig. 3C) and the passive planar area $\mathrm{C} 3$ (Fig. 3D) were healthy and adhered well.
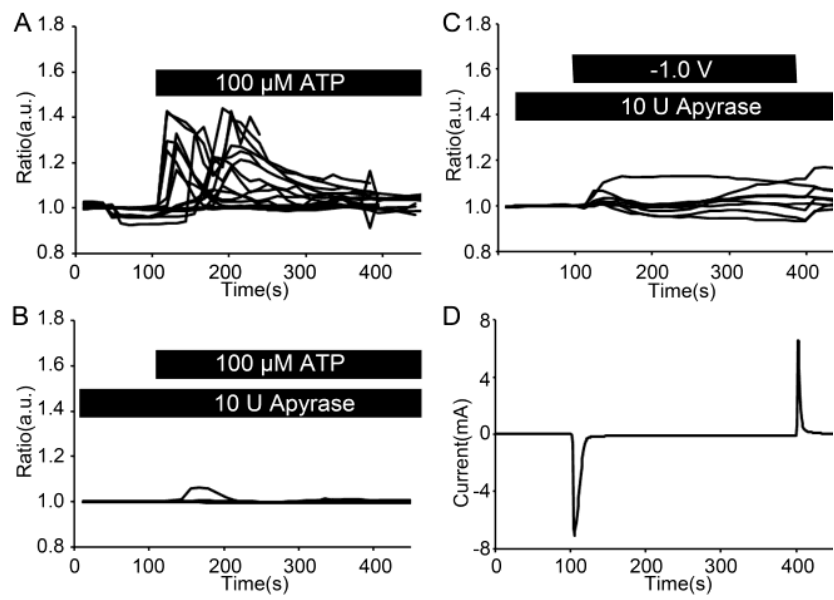

Fig. $4 \mathrm{Ca}^{2+}$ responses induced by ATP and blocked by apyrase. (A) Addition of $100 \mu \mathrm{M}$ ATP induces an increase in intracellular $\mathrm{Ca}^{2+}$. (recordings from several cells from four different experiments). (B) The addition of apyrase blocks the effect of adding extracellular ATP on 80 intracellular $\mathrm{Ca}^{2+}$. (recordings from several cells from three different experiments). (C) The addition of apyrase blocks the intracellular $\mathrm{Ca}^{2+}$ increase caused by the mechanical stimulation of the microactuator A. Only small fluctuations are present at time points where the voltage operating the PPy microactuators is altered (recordings from several cells 85 from three different experiments). (D) Time vs. current plot showing the currents associated with the voltage changes to activate the PPy microactuators

The volume change of PPy upon electrochemical switching is predominantly caused by ion migration in and out of the PPy bulk 90 during electrochemical reduction and oxidation. The electroactive planar area $\mathrm{C} 2$ was designed as a control for the effects of the addressing potential and associated redox reactions. We monitored intracellular $\mathrm{Ca}^{2+}$ concentrations in cells on area $\mathrm{C} 2$ and the passive control area $\mathrm{C} 3$ during chip activation. In some 95 cells on the electroactive planar PPy area $\mathrm{C} 2 \mathrm{Ca}^{2+}$ concentration peaks that coincided with the application of the voltage at $100 \mathrm{~s}$ (Fig. 3E) were seen. The switching from $-1.0 \mathrm{~V}$ to $0.0 \mathrm{~V}$ vs $\mathrm{Ag} / \mathrm{AgCl}$ at $400 \mathrm{~s}$ also resulted in transient $\mathrm{Ca}^{2+}$ fluctuations in some cells (Fig. 3E). On the passive area C3 no fluctuations 100 associated with the activation of the chip were found (Fig. 3F).

\section{$\mathrm{Ca}^{2+}$ signaling is mediated via autocrine ATP signalling}

One of the most important mechanosensing mechanisms in 
MDCK cells is auto- and paracrine ATP signaling. ${ }^{11}$ To investigate the role of ATP signaling in the $\mathrm{Ca}^{2+}$ responses induced by the microactuator chip we treated the MDCK cells with $100 \mu \mathrm{M}$ ATP which resulted in a rapid and passing $\mathrm{Ca}^{2+}$ 5 increase with the same amplitude as the $\mathrm{Ca}^{2+}$ increase induced by the microactuator A (Fig. 4A). This $\mathrm{Ca}^{2+}$ increase induced by ATP could be almost completely blocked by adding $10 \mathrm{U} / \mathrm{mL}$ of the ATPase apyrase (Fig. 4B). The addition of apyrase also had an obvious inhibitory effect on the $\mathrm{Ca}^{2+}$ response induced by the 10 microactuator A on the microactuator chip (Fig. 4C).

\section{Discussion}

The results of this study show that the PPy microactuator chip is a useful tool for the study of mechanical stimulation on the cellular level. The design of the chip makes it compatible with other cell 15 biology tools such as fluorescence based live imaging of

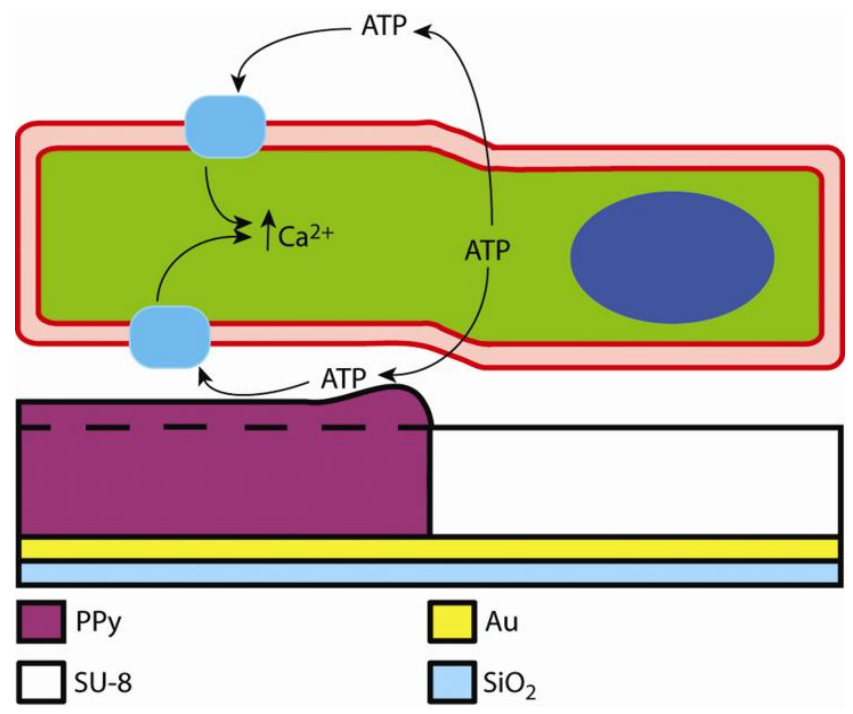

Fig. 5 Schematic illustration of the PPy expansion and resulting cellular $\mathrm{Ca}^{2+}$ response induced by autocrine ATP signalling.

intracellular $\mathrm{Ca}^{2+}$ and the intrinsic control surfaces enable the 20 identification of artefacts induced by the activation potential.

PPy reaches full expansion at about $90 \mathrm{~s}$, but the reduction current drops in less than $30 \mathrm{~s}$ (Compare Fig. 1E and 4D). This is because the expansion has two regimes. First, a fast expansion due to the intercalation of ions, followed by a slower phase of the 25 osmotic expansion. ${ }^{40}$ In contrast to other studies ${ }^{32,36}$, the PPy actuators did not shrink when we applied an oxidation potential nor could they be cycled. It might be that the PPy is mechanically attached to SU-8, thus constricting the shrinking. Also, the perpendicular expansion of these patterned PPy lines was less 30 than that observed for planar, unpatterned PPy. ${ }^{32,} 36$ Both phenomena were also noticed for PPy based wettability switches. ${ }^{34}$ In both the wettability switches and the microactuator chip presented here, patterned PPy was combined with a SU-8 pattern. The perpendicular expansion in the wettability switches 35 was of the same magnitude, $8.7 \%$ for a $12.7 \mu \mathrm{m}$ thick layer and $15 \%$ for a $20 \mu \mathrm{m}$ layer, as measured here. The batch of devices that was used for the stimulation in DMEM had slightly larger PPy. We noticed that the expansion was somewhat larger than the other batches. This might be because the PPy in this batch was
40 taller than the SU-8, thus was less constricted by the SU-8 and had better access to the electrolyte, which could explain the slightly increased expansion. In addition, we did observe fully reversible expansion of these mechanostimulation devices of the same order of magnitude ( 20-30\%) as published previously ${ }^{32,36}$ 45 when we omitted the SU-8 pattern, confirming that SU-8 might be the cause of the one-time actuation with reduced expansion.

It is interesting to see that the dynamics of the cellular $\mathrm{Ca}^{2+}$ response correlate with the PPy expansion which reaches a plateau after $90 \mathrm{~s}$ (compare Fig. 1E and 2F). In contrast, when ${ }_{50}$ ATP is added extrinsically or when the cells are introduced to a pressure pulse, both of which are suggested to induce release of ATP, the intracellular $\mathrm{Ca}^{2+}$ increase is relatively steep. ${ }^{11}$ One might speculate that the gradual stretch induced by the PPy swelling is accompanied by a gradual increase of ATP release 55 and that this is the reason for the gradual increase in the $\mathrm{Ca}^{2+}$ signal. Since this intracellular $\mathrm{Ca}^{2+}$ response was inhibited by apyrase, we believe that the primary mechanism affected by the microactuators is the auto- and paracrine ATP signalling. Also, mechanical stretch of MDCK cells is associated with ATP release 60 which is in accordance with the results achieved with the microactuator chip where mechanical stimulation is applied at basal side of the cells. ${ }^{12}$ The ATP binds to purinergic receptors which induce $\mathrm{Ca}^{2+}$ signalling in the MDCK cells. These receptors are expressed both basolateral and apical as depicted in Fig. 5. ${ }_{65}$ The MDCK cell line originates from the distal tubuli and develops apical sensory cilia when they are cultured to full confluence. In the distal tubuli these sensory cilia are suggested to be involved in the sensing of urine flow. ${ }^{10}$ The sensory cilia and the autocrine ATP signalling has been suggested to function 70 independently of each other. ${ }^{11}$ The microactuator was designed to apply stretch stimuli to the basal side of the cells, however in future versions of the microactuator chip microfluidics for application of shear flow could be integrated in the chip. This will make it possible to investigate combinations of different kinds of 75 mechanical stimuli.

The applied potential and associated ion currents cause the swelling of the PPy and are thus critical for the functioning of the microactuator chip, but they may also be a limitation for the use of the device since these ion currents may depolarize cells or in 80 other ways induce responses that are not due to the mechanical stimulation. In these experiments we have seen some variation in the $\mathrm{Ca}^{2+}$ response both in cells on the microactuators $\mathrm{A}$, where occasional cells with a biphasic response were seen, but also on the electroactive planar PPy area $\mathrm{C} 2$, where some cells were 85 totally unaffected while others had a transient $\mathrm{Ca}^{2+}$ peak associated with changing the applied potential. This variation may reflect on the heterogeneous nature of the wild type MDCK cell line, which contains subtypes of cells with different electric characteristics and expression of different ion channels. ${ }^{41}$ 90 However, if the subtypes of MDCK cells are identified, depolarization due to ion currents should not pose a serious issue, which can be the case with excitable cells like neurons. One alternative to overcome the problems caused by the activation potential is to pharmacologically block voltage operated ion 95 channels. Electrical stimulation can be coupled to mechanical effects on the plasma membrane of the cell through a phenomenon known as electrostriction. However, the magnitude 
of displacement of the membrane induced by electrostriction is likely to be orders of magnitude less than what is achieved with the microactuator.

\section{Conclusions}

5 Previously, the regulatory signals for biological and medical mechanisms have been dominated by a focus on different biochemical stimulation factors. However, there is an increasing interest in the relevance of mechanical cues for physiological functions and pathological conditions on the cellular and 10 macromolecular level. ${ }^{42-44}$ In this study we used renal epithelial cells since it is a cell type for which mechanical stimulation is highly relevant, but there are a number of other cell types that also are dependent on mechanical stimulus for their function, such as osteoblasts, endothelial cells, and myocytes, which are of 15 interest to study with these devices. Since the chip is produced with microfabrication processes there is potential for further miniaturization as well as increased complexity. An array type of device with individually addressable microactuators is envisioned, allowing for cells to be exposed to mechanical 20 stimulation at different strains, strain rates, and/or frequencies within the same culture. We are currently redesigning the chips by replacing or omitting the SU8 in order to achieve reversible actuation and thus extending the application areas of the device.

Conclusively, we show that by combining conjugated 25 polymers and microfabrication we can produce a chip for mechanical stimulation on a cellular level, which is fully compatible with traditional cell biology tools. The chip allowed us to target and monitor a specific $\mathrm{Ca}^{2+}$ dependent mechanotransduction process in renal epithelial cells. This 30 illustrates how this technology is a highly relevant tool in contemporary life science.

\section{Acknowledgements}

The authors acknowledge XianjunWang for fruitful discussions and Rolf Nybom and Markus Nybom for their assistance with the

${ }_{35}$ SEM. The research was financed by the Swedish Foundation for Strategic Research (OBOE Strategic Research Center for Organic Bioelectronics), VINNOVA, the Knut and Alice Wallenberg Foundation, the Royal Swedish Academy of Science, and the Önnesjö Foundation.

\section{${ }_{40}$ Notes and references}

${ }^{a}$ Karolinska Institutet, Swedish Medical Nanoscience Center, Department of Neuroscience, SE-171 77 Stockholm, Sweden.

${ }^{b}$ Linköping University, Department of Science and Technology, Organic Electronics, SE-601 74 Norrköping, Sweden, E-mail: edwin.jager@liu.se 45

1. C. Hahn and M. A. Schwartz, Nature Reviews Molecular Cell Biology, 2009, 10, 53-62.

2. M. Chalfie, Nature Reviews Molecular Cell Biology, 2009, 10, 44-52.

3. V. Vogel and M. Sheetz, Nature Reviews Molecular Cell Biology, 50 2006, 7, 265-275

4. B. Geiger, J. P. Spatz and A. D. Bershadsky, Nat Rev Mol Cell Biol, 2009, 10, 21-33.

5. S. I. Sukharev, P. Blount, B. Martinac, F. R. Blattner and C. Kung, Nature, 1994, 368, 265-268.
55 6. K. Hayakawa, H. Tatsumi and M. Sokabe, Journal of cell science, 2008, 121, 496-503.

7. R. Sharif-Naeini, A. Dedman, J. H. A. Folgering, F. Duprat, A. Patel, B. Nilius and E. Honore, Pflugers Archiv-European Journal of Physiology, 2008, 456, 529-540.

60 8. K. Furuya, M. Sokabe and S. Furuya, Journal of cell science, 2005, 118, 3289-3304.

9. H. A. Praetorius and K. R. Spring, Annual review of physiology, 2005, 67, 515-529.

10. H. A. Praetorius and K. R. Spring, The Journal of membrane biology, $65 \quad 2001, \mathbf{1 8 4}, 71-79$.

11. H. A. Praetorius, J. Frokiaer and J. Leipziger, American journal of physiology, 2005, 288, F133-141.

12. P. A. Insel, R. S. Ostrom, A. C. Zambon, R. J. Hughes, M. A. Balboa, D. Shehnaz, C. Gregorian, B. Torres, B. L. Firestein, M. Xing 70 and S. R. Post, Clinical and experimental pharmacology \& physiology, 2001, 28, 351-354.

13. N. Wang, J. P. Butler and D. E. Ingber, Science (New York, N.Y, 1993, 260, 1124-1127.

14. E. W. K. Young and C. A. Simmons, Lab on a Chip - Miniaturisation 75 for Chemistry and Biology, 2010, 10, 143-160.

15. A. J. Banes, J. Gilbert, D. Taylor and O. Monbureau, Journal of cell science, $1985, \mathbf{7 5}, 35-42$.

16. J. Garvin, J. Qi, M. Maloney and A. J. Banes, Tissue engineering, 2003, 9, 967-979.

80 17. M. K. Elfervig, J. T. Minchew, E. Francke, M. Tsuzaki and A. J. Banes, Journal of cellular biochemistry, 2001, 82, 290-298.

18. A. Ashkin and J. M. Dziedzic, Science (New York, N.Y, 1987, 235, $1517-1520$

19. A. Ashkin, J. M. Dziedzic and T. Yamane, Nature, 1987, 330, 769$85-771$

20. C.-A. Lamontagne, C. Cuerrier and M. Grandbois, Pflügers Archiv European Journal of Physiology, 2008, 456, 61-70.

21. N. Wang, J. P. Butler and D. E. Ingber, Science, 1993, 260, 11241127.

90 22. K. J. Gilmore, M. Kita, Y. Han, A. Gelmi, M. J. Higgins, S. E. Moulton, G. M. Clark, R. Kapsa and G. G. Wallace, Biomaterials, 2009, 30, 5292-5304.

23. T. Nyberg, A. Shimada and K. Torimitsu, Journal of Neuroscience Methods, 2007, 160, 16-25.

95 24. K. A. Ludwig, J. D. Uram, J. Yang, D. C. Martin and D. R. Kipke, Journal of Neural Engineering, 2006, 3, 59-70.

25. J. Y. Wong, R. Langer and D. E. Ingber, Proceedings of the National Academy of Sciences of the United States of America, 1994, 91, 3201-3204.

100 26. J. Isaksson, P. Kjall, D. Nilsson, N. D. Robinson, M. Berggren and A. Richter-Dahlfors, Nature Materials, 2007, 6, 673-679.

27. K. Svennersten, M. Bolin, E. W. H. Jager, M. Berggren and A. Richter-Dahlfors, Biomaterials, 2009, 30, 6257-6264.

28. Q. Pei and O. Inganäs, Adv. Mater., 1992, 4, 277-278.

105 29. T. F. Otero, E. Angulo, J. Rodriguez and C. Santamaria, Journal of Electroanalytical Chemistry, 1992, 341, 369-375.

30. E. Smela, O. Inganäs, Q. Pei and I. Lundström, Adv. Mater., 1993, 5, 630-632.

31. E. W. H. Jager, E. Smela and O. Inganäs, Science, 2000, 290, 1540$110 \quad 1545$ 
32. E. Smela and N. Gadegaard, Adv. Mater., 1999, 11, 953-957.

33. Y. Berdichevsky and Y.-H. Lo, Polymer Microvalve Based on Anisotropic Expansion of Polypyrrole, 2004.

34. X. Wang, M. Berggren and O. Inganäs, Langmuir, 2008, 24, 5942-

55948

35. E. W. H. Jager, in Iontronics - Ionic carriers in organic electronic materials and devices, eds. J. Leger, S. Carter and M. Berggren, CRC Press, 2010, ch. 8, pp. 141-162.

36. WO2009038501, 2007.

10 37. A. S. Andersson, F. Bäckhed, A. Von Euler, A. Richter-Dahlfors, D. Sutherland and B. Kasemo, Biomaterials, 2003, 24, $3427-$ 3436.

38. R. Marie, S. Schmid, A. Johansson, L. Ejsing, M. Nordström, D. Häfliger, C. B. V. Christensen, A. Boisen and M. Dufva,

15 Biosensors and Bioelectronics, 2006, 21, 1327-1332.

39. S. Pellegrin and H. Mellor, Journal of cell science, 2007, 120, 34913499.

40. L. Bay, T. Jacobsen, S. Skaarup and K. West, J. Phys. Chem. B, 2001, 105, 8492-8497.

20 41. M. Gekle, S. Wunsch, H. Oberleithner and S. Silbernagl, Pflugers Archiv-European Journal of Physiology, 1994, 428, 157-162.

42. V. Vogel and M. P. Sheetz, Current opinion in cell biology, 2009, 21, 38-46.

43. K. R. Levental, H. Yu, L. Kass, J. N. Lakins, M. Egeblad, J. T. Erler,

25 S. F. T. Fong, K. Csiszar, A. Giaccia, W. Weninger, M. Yamauchi, D. L. Gasser and V. M. Weaver, Cell, 2009, 139, 891-906.

44. F. J. Alenghat, J. D. Tytell, C. K. Thodeti, A. Derrien and D. E. Ingber, Journal of cellular biochemistry, 2009, 106, 529-538. 